DOSSIÊ

\title{
Tendências da dinâmica do comércio mundial pós-covid-19
}

Trends in post-covid-19 world trade dynamics vallace мoreili Lima*
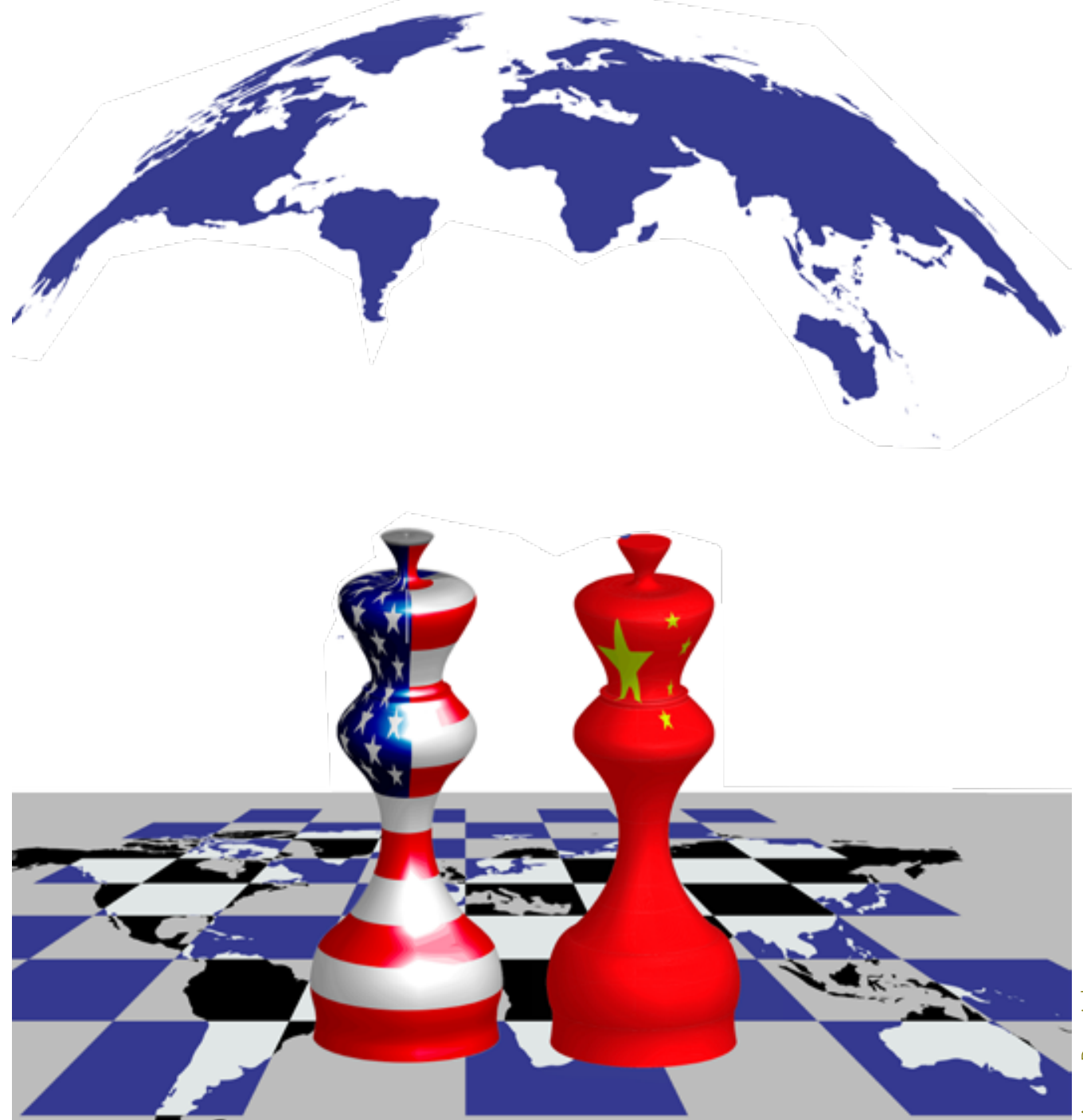

60 


\section{RESUMO}

Um dos principais aspectos que marcou o comércio internacional foi a fragmentação da produção, a qual fez com que fosse extinta a necessidade de adquirir competência em todos os aspectos da produção de um bem e permitiu que muitos países pudessem se associar a uma rede de cooperação transfronteiriça, partilhando a produção e especializando-se em apenas uma ou algumas etapas das atividades de produção envolvidas na confecção de um bem final. Entretanto, algumas características dessa lógica, como as assimetrias entre as nações e o forte comércio intrarregional, provocaram questionamentos sobre alguns princípios que estão por trás do conceito de cadeias globais de valor, como a não necessidade de política industrial e a defesa do livre comércio. Com a atual crise mundial resultante da covid-ı, algumas tendências no comércio internacional apontam para uma nova dinâmica, com a qual as políticas industriais na defesa das cadeias produtivas internas ganham cada vez mais relevância. Nesse sentido, a hipótese é a de que, além de as novas tecnologicas enfraquecerem o comércio via cadeias globais de valor, vários países teriam anunciado medidas de políticas industriais e tecnológicas para fortalecer suas estruturas produtivas internas nacionais, intensificando assim a construção de uma nova tendência da economia internacional.

Palavras-chave: Cadeias globais de valor. Covid-I9. Políticas industriais.

\section{ABSTRACT}

With the rise of what was called productive globalization, one of the main aspects of international trade was the fragmentation of production, which made the need for countries and companies to acquire competence in all aspects of the production of a good and it has enabled many countries to join an international cooperation network, where countries fragment their production and specialize in only one or a few stages of production activities involved in the manufacture of a final good. However, some characteristics of this logic, such as the asymmetries between nations and the strong intraregional trade, caused questions about some principles that are behind the concept of global value chains, such as the non-importance of industrial policy and the defense of free world trade. The current global crisis resulting from covid-I9 has created some trends in international trade that point to a new dynamic, wich industrial policies in defense of internal production chains are becoming increasingly relevant. Therefore, the hypothesis of this paper is that in addition to the new technologies that weaken trade via global value chains, several countries have implemented industrial and technological policy measures to strengthen their domestic internal productive structures, thus intensifying the construction of a scenario for a new trend in the international economy.

Keywords: Global value chains. Covid-I9. Industrial policies. 


\section{INTRODUÇ̃̃O}

A economia mundial experimentou nas três últimas décadas um intenso processo de globalização, marcado por modificação de paradigma do sistema produtivo internacional. Particularmente, do ponto de vista da dinâmica produtiva e do comércio internacional, o sistema produtivo tradicional, com uma ampla gama de indústrias, deixou de ser restrito ao âmbito nacional para estar cada vez mais envolvido em uma rede de negócios de caráter fragmentado entre empresas e disperso entre países em escala regional e global, conforme a tendência de desverticalização (outsourcing) e deslocalização (offshoring) produtiva sob o comando das transnacionais. Estas fatiam a manufatura desde a concepção do produto, passando por insumos e componentes, até o consumo final, com as etapas intermediárias ocupando mais de dois terços do comércio internacional e passando a ser mais importantes do que a etapa final do processo produtivo. Esse processo ficou conhecido como cadeias globais de valor (CGVs).

Estevadeordal, Suominen e Blyde (2012), Baldwin e Robert-Nicoud (2004; 20I0) e Lima (20I7a) afirmam que um dos principais aspectos das CGVs é a fragmentação da produção, a qual faz com que seja extinta a necessidade de adquirir competência em todos os aspectos da produção de um bem e permite que os países em desenvolvimento possam se associar a uma rede de cooperação transfronteiriça, partilhando a produção e especializando-se em apenas uma ou algumas etapas das atividades de produção envolvidas na confecção de um bem final. Esse tipo de especialização, segundo os autores, permitiria que os países em desenvolvimento participassem de uma nova estratégia de divisão internacional do trabalho.

Diante dessas transformações, muitos autores se apressaram em afirmar que política industrial não fazia mais sentido nenhum. Por exemplo, de acordo com Wade (20I5), Gary Becker afirmou que a melhor política industrial é não ter nenhuma política industrial. John Williamson, cristalizador do Consenso de Washington, afirmou que existem poucos registros da política industrial ao longo da história que sugerem que o Estado é muito bom em escolher setores vencedores. Lawrence Summers, ex-economista-chefe do Banco Mundial e professor em Harvard, afirmou que o governo e a política industrial se constituem em "um capital de risco de baixa qualidade".

A problemática dessa narrativa reside no fato de que vários estudos mostram que o processo de distribuição das CGVs tem se constituído de forma assimétrica, com algumas regiões avançando substancialmente em sua inserção no comércio mundial via CGVs, como é o caso dos países da região da Ásia, Europa e América do Norte, enquanto outros países de regiões como África e América Latina ficam à margem desse processo, como é o caso do Brasil.

Qual a origem dessas assimetrias de industrialização e inserção nas CGVs? Uma análise mais criteriosa das trajetórias de desenvolvimento dos países da Ásia e de países centrais mostra que a política industrial se faz presente nesses países, con- 
tribuindo para a forma diferenciada de inserção internacional, na medida em que essas políticas promoveram um profundo upgrading nas suas estruturas produtivas nacionais, refletindo-se em sua inserção internacional mais competitiva.

O comércio via cadeias globais de valor, para muitos estudos, tem apresentado um relativo arrefecimento, que pode indicar uma nova dinâmica do comércio mundial. Em estudos recentes, a Organização para a Cooperação e Desenvolvimento Econômico (OCDE) tem observado evidências tem observado evidências de que a fragmentação internacional da produção tem perdido impulso, principalmente em decorrência do crescimento da importância das tecnologias da Quarta Revolução Industrial (como TI, robótica, inteligência artificial, automação, $3 \mathrm{D}$ e digitização), com possível e significativo redesenho das características da economia global e impactos disruptivos nas cadeias globais de valor (OCDE, 2017). Tudo indica que a crise desencadeada pela covid-I9 tem acentuado esse movimento de necessidade de fortalecimento de estruturas produtivas internas no mundo.

A partir desse cenário, a problemática levantada pelo presente artigo é identificar se estamos diante de uma nova configuração do comércio internacional. Para responder a essa questão, é relevante entender a lógica do comércio das cadeias globais de valor e suas contradições e verificar se no cenário atual há elementos de crise dessa dinâmica de fragmentação e o surgimento de uma nova forma de organização do comércio. A hipótese é a de que, além das novas tecnologicas enfraquecerem o comércio via cadeias globais de valor, vários países teriam implementado medidas de políticas industriais e tecnológicas para fortalecer suas estruturas produtivas internas nacionais, intensificando assim a construção de uma nova tendência da economia internacional, pela qual o fortalecimento das cadeias produtivas internas se torna essencial como mecanismo de garantia da soberania nacional, particularmente considerando os conflitos geopolíticos que se acentuaram com a crise provocada pela covid-I9.

Além desta introdução, o artigo é composto de mais quatro seções. Na seção 2, apresentam-se algumas características da dinâmica das cadeias globais de valor. $\mathrm{Na}$ seção 3, discutem-se duas evidências do comércio pela lógica das cadeias globais de valor: as assimetrias entre os países e o predomínio do comércio intrarregional. $\mathrm{Na}$ seção 4, faz-se um debate sobre indícios de um enfraquecimento das cadeias globais de valor anterior à crise causada pela covid-I9. Na seção 5, identificamos alguns dos impactos dessa crise sobre o comércio mundial, o que aponta para uma nova tendência. Por fim, na conclusão, algumas breves reflexões sobre as janelas de oportunidades que a crise atual oferece, particularmente considerando a relevância do papel da política industrial.

\section{A DINÂMICA DAS CADEIAS GLOBAIS DE VALOR (CGVS)}

A literatura traz muitas designações diferentes para o termo fragmentação, processo que já acontece desde os anos I980. Feenstra (1998) refere-se ao processo 
de fragmentação como desintegração da produção. Hummels, Ishii e Yi (200I) falam em especialização vertical da produção. Baldwin (2013) relaciona a desagregação ao processo histórico de desmembramento da produção (unbundling) e faz um link da primeira separação da produção com a segunda, mostrando que a desagregação não é um fenômeno novo. Baldwin (2013) destaca que, em meados do século XIX, o impacto da aplicação do vapor nos meios de transporte (surgimento da locomotiva e navio a vapor e das ferrovias) provocou uma revolução na produção ao separar geograficamente o consumo da produção. A separação foi lucrativa por causa dos ganhos com as economias de escala e com a vantagem comparativa. Ele referiu-se a esse momento histórico como first unbundling. O segundo momento histórico da desagregação (second unbundling) ocorre a partir da década de 1980 e diz respeito à revolução das TICs (tecnologias de informação e comunicação, espécie de interação tecnológica entre computadores, telecomunicação e softwares). A revolução nos meios de comunicação e informação impactou o espaço enquanto distância (e consequentemente o tempo) porque quebrou a barreira da distância com a possibilidade de coordenação. Ou seja, as etapas de produção anteriormente realizadas dentro da empresa ou na sua vizinhança podiam agora ser dispersas geograficamente, na medida em que as TICs permitiam a coordenação das atividades produtivas a distância.

A separação da produção agora era lucrativa porque havia grandes diferenças de salários entre o Norte e o Sul, e essas diferenças salariais poderiam ser exploradas pelas empresas multinacionais (BALDWIN, 20I3). Feenstra (1998) acrescenta que o mundo se tornou mais integrado e que a integração atual não tem comparação na história. Para o autor, a intensificação da integração do comércio veio acompanhada da desintegração da produção entre diversas empresas e entre diferentes países. As firmas transnacionais líderes no processo produtivo entenderam que neste estágio do capitalismo podem lucrar mais transferindo tarefas produtivas para outras empresas e outros países, de modo que podem distribuir a produção entre o seu mercado e os mercados dos países periféricos.

Segundo Baldwin e Robert-Nicoud (2004; 20I0), a fragmentação é marcada pela separação geográfica de atividades envolvidas na produção de um bem ou um serviço, com dois ou mais países participando desse processo. Com isso, a organização internacional da produção aumentou substancialmente as interdependências entre as economias em escala mundial, com o comércio apresentando um crescimento constante em suas relações, via insumos e serviços intermediários da produção.

Esse processo de expansão da produção internacional passou a ser mais conhecido na literatura como cadeias globais de valor (CGVs). Vários estudos ${ }^{1}$ mostram que a ideia de cadeias globais de valor está relacionada a cadeias de fornecedores, aos processos de fragmentação da produção, a uma estratégia de especialização vertical, produção em multiestágios, subcontratação, realocação, offshoring e outsourcing. O conceito de CGVs também implica a estratégia de as empresas fragmentarem seus

1 Ver: BALDWIN e ROBERT-NICOUD (2004; 2010); JONES e KIERZKOWSKI (1990); GROSSMAN e ROSSIHANSBERG (2008); OCDE (2013). 
A ideia de cadeias globais de

valor está relacionada a cadeias

de fornecedores, aos processos

de fragmentação da produção, a

uma estratégia de especialização

vertical, produção em multiestágios,

subcontratação, realocação,

offshoring e outsourcing

processos de produção e alocarem suas atividades produtivas em vários países e regiões, formando com isso cadeias globais de valor que recriam a divisão internacional do trabalho na economia mundial. Nesse processo, aumentam os fluxos de investimento direto estrangeiro (IDE), inserindo novas regiões nos mercados internacionais e estimulando o setor de serviços, particularmente os relacionados às indústrias de transformação, que vão ganhando maior espaço na economia mundial.

Segundo Sturgeon et al. (2013) e Baldwin e Robert-Nicoud (2004; 2010), os países em desenvolvimento podem se beneficiar muito com a reestruturação da produção via CGVs na medida em que o comércio, os investimentos e os fluxos de conhecimento que sustentam as CGVs fornecem mecanismos que estimulam o rápido aprendizado, a inovação e o upgrading na estrutura industrial dos países. Os autores afirmam que as CGVs podem propiciar às empresas locais melhor acesso à informação, inserção em novos mercados com demandas mais sofisticadas e criar oportunidades para a rápida aprendizagem tecnológica e a aquisição de conhecimentos. Além do mais, em geral, as transações e investimentos relacionados às CGVs vêm acompanhados de sistemas de controle de qualidade e de padrões de negócios globais dominantes, fazendo com que as empresas e indivíduos desses países sintam-se pressionados a adquirir novas competências e habilidades por meio da participação em CGVs.

Nesse debate fica claro que a fragmentação é parte das CGVs, mas este é um fenômeno mais abrangente. Enquanto a fragmentação é uma categoria anterior, que envolve a dispersão da cadeia de produção entre as fronteiras nacionais e a desverticalização da produção de uma empresa, as CGVs são uma categoria posterior, pois acrescenta à dimensão da fragmentação a ideia de comando e coordenação da cadeia, isto é, adiciona a estrutura de governança. Essa governança é exercida pelas empresas de alcance internacional que coordenam as atividades produtivas. Portanto, de forma resumida, o conceito de fragmentação envolve a produção de bens e serviços por diversas empresas em diferentes países. Essas empresas adquirem insumos e compo- 
nentes que atravessam as fronteiras nacionais até a produção de um bem final. Já a CGV pode ser entendida como uma cadeia de produção fragmentada gerida por uma estrutura de governança. Logo, a CGV é uma abordagem conceitual ampliada da fragmentação produtiva, em razão de abarcar o complexo de relações e interações entre as empresas participantes que formam a estrutura de governança. E é essa governança que determina a organização e a lógica de funcionamento da cadeia de valor (FEENSTRA, I998; LIMA, 20I7a; CARNEIRO, 20I7).

Assim, pela fragmentação via CGVs, as empresas-líderes transnacionais controlam e coordenam o sistema de produção mundial de um amplo conjunto de bens e serviços em diversas indústrias. O papel de liderar a cadeia por via da governança tem o objetivo de capturar a maior parte do valor adicionado gerado na produção. Isso implica que a estrutura de governança obedece a uma determinada hierarquia, formada a partir das posições que as empresas ocupam na cadeia de valor. A depender dessas posições, as empresas podem influenciar mais ou menos a organização da cadeia e capturar o valor correspondente à sua posição.

Por exemplo, as empresas que lideram os elos mais elevados ou mais nobres da cadeia, ou que neles ocupam posições, capturam maior valor adicionado, enquanto as empresas que ocupam os elos mais baixos ou menos nobres da cadeia apropriam-se de menor valor adicionado. Nos elos mais elevados situam-se as empresas que possuem marcas de alcance mundial, as que têm ativos específicos e estratégicos e as que detêm competências tecnológicas singulares e difíceis de replicar. Em razão disso, comandam o funcionamento, estabelecem as regras contratuais e os padrões de qualidade etc. e, consequentemente, apropriam-se do maior valor criado na cadeia produtiva. Por outro lado, as empresas sem essas qualificações ocupam posições subalternas e facilmente substituíveis e, geralmente, estão concentradas em países periféricos (GEREFFI; HUMPHREY; STURGEON, 2005).

\section{EVIDÊNCIAS DO COMÉRCIO PELA LÓGICA DAS CADEIAS GLOBAIS DE VALOR}

Um dos princípios da dinâmica do comércio internacional via cadeias globais de valor reside na crença de que ela proporcionaria um equilíbrio maior na divisão internacional do trabalho, ou seja, seria uma relação mais simétrica entre as nações na economia internacional, pois a fragmentação proporcionaria uma lógica de comércio em função da qual nenhum país teria a necessidade de adquirir competência em todos os aspectos da produção de um bem e que permitiria aos países em desenvolvimento se associar a uma rede de cooperação transfronteiriça, partilhando a produção e especializando-se em apenas uma ou algumas etapas das atividades de produção envolvidas na confecção de um bem final.

Entretanto, duas evidências empíricas mostram algumas problemáticas dessa narrativa: a) primeiro, o processo de distribuição das CGVs tem se constituído de forma assimétrica, com algumas regiões apresentando ganhos com sua inserção no 
comércio mundial via CGVs, enquanto outros países e regiões ficam à margem desse processo; b) segundo, predomina uma lógica de comércio intrarregional, contrário aos princípios de livre comércio e abertura para novas relações comerciais.

Em relação à problemática dos desequilíbrios nas formas de inserção dos países nas cadeias globais de valor, Estevadeordal, Suominen e Blyde (2012), assim como um estudo da OCDE mostram que a reestruturação da produção via CGVs tem se constituído de forma assimétrica, com algumas regiões avançando substancialmente em sua inserção no comércio mundial, como é o caso dos países da região da Ásia, Europa e América do Norte, enquanto outros países de regiões como África e América Latina ficam à margem desse processo, como é o caso do Brasil. No caso do Brasil, por exemplo, os indicadores do estudo da OCDE deixam nítido que a economia brasileira ficou à margem do processo de reestruturação das cadeias globais de valor, apresentando baixa integração da sua cadeia produtiva nas CGVs (OECD, 20I3).

A nova configuração do comércio exigiu das instituições internacionais a produção de novos indicadores e medidas que fossem mais aptos para identificar quais países e regiões estão mais envolvidos nas CGVs. O melhor exemplo disso é a base de dados conhecida como TiVA, produzida pela $\mathrm{OCDE}^{2}$, a qual fornece insights sobre redes de produção globais e cadeias de suprimentos. Entretanto, por exemplo, se esses novos indicadores mostram assimetria entre os países, não deixam em evidência os motivos de predominarem inserções diferenciadas entre os países da região asiática quando comparados com a América Latina, nem como isso pode ter impactado no processo de crescimento diferenciado dessas regiões. Para Estevadeordal, Suominen e Blyde (20I2) e Koopman et al. (20II), essa diferença de participação nas CGVs pode estar relacionada, entre outras coisas, à força da aproximação dos países aos grandes mercados regionais, assim como pode ser resultado de políticas industriais.

Para Carneiro (2007), por exemplo, a prevalência da globalização produtiva na Ásia em desenvolvimento e o predomínio da globalização financeira na América Latina explicam as diferenças de trajetória entre as regiões. Em sentido convergente com este último argumento, muitos analistas defendem a tese de que o sucesso do Leste e Sudeste Asiático tem a ver com a forte intervenção governamental com políticas industriais orientadas para setores estratégicos, como afirma Lima (20I7b).

Segundo alguns autores, para países periféricos a inserção nas cadeias globais de valor pode resultar em maiores problemáticas do que benefícios. Por exemplo, Gibbon, Bair e Ponte (2008) afirmam que, por um lado, a atividade econômica nos países desenvolvidos se concentra em etapas que adicionam mais valor, como: concepção e desenvolvimento de produtos; financiamento da produção e do consumo; comercialização; e serviços de prestação de comunicações globais. Por outro lado, os países periféricos estão cada vez mais dedicados à produção per se via offshoring e à provisão de alguns serviços relacionados à fabricação, os quais agregam baixo valor às cadeias,

2 O banco de dados Trade in Value Added (TiVA) é uma coleção de medidas que podem fornecer insights sobre redes de produção globais e cadeias de suprimentos além do que é possível com estatísticas de comércio convencionais (OECD.STAT, 2020). 
sendo que algumas economias permanecem dominadas pela agricultura e atividades extrativistas. Isso aponta para o fato de que a lógica do comércio via princípios das CGVs mantém as assimetrias entre as nações, deixando em evidência que o processo simples de abertura econômica não é o caminho mais viável para que as economias periféricas logrem o upgrading industrial e com isso ocupem uma posição mais competitiva nas redes fragmentadas da produção mundial (GIBBON; BAIR; PONTE, 2008).

Esse processo assimétrico do comércio internacional tem relação com a distribuição de riscos e oportunidades, pois isso está estritamente relacionado ao posicionamento de uma empresa ou país dentro de uma cadeia de valor. Assim como a natureza dessa cadeia, para economias mais pobres a produção em cadeias tem um potencial ainda maior de afetar seus gerenciamentos de riscos, principalmente considerando a posição de países subordinados na cadeia produtiva que essas economias assumem, que as tornam submissas às ações das empresas-líderes que definem os requisitos e padrões de desempenho, assim como a condição de entrada e mobilidade dentro das CGVs. Esse ambiente reduz o potencial de mitigar crises via políticas protecionistas, ou seja, agrava as condições de vulnerabilidade externa dos países periféricos (GIBBON; BAIR; PONTE, 2008; GEREFFI; LUO, 20I4; GEREFFI, 20I4).

Para Pinto, Fiani e Corrêa (20I5), cada etapa da cadeia global de valor apresenta diferentes intensidades de fatores e tecnologia, como também diferentes capacidades de geração de valor, de transbordamento sobre os outros setores e de impactos sobre a balança comercial. Com isso, as atividades internalizadas pelas firmas terão influência significativa sobre seu desempenho de longo prazo e também sobre o dinamismo econômico dos países que as sediam, o que se torna uma das origens das diferenças de inserção nas CGVs.

Esses princípios, para os autores, deixam nítidas as assimetrias nas condições de inserção dos países nas cadeias globais, dado que, em termos de criação de valor, as atividades que geram maior valor agregado (VA) são normalmente aquelas mais intensivas em conhecimento e tecnologia e que, em contrapartida, tendem a gerar menos empregos, embora de maior qualificação. Já nas atividades intensivas em trabalho, a criação de empregos é certamente superior; contudo, com predominância de baixa qualificação nos postos de trabalho gerados. Ou seja, isso mostra que uma estratégia consistente de desenvolvimento deve distinguir o efeito da inserção nas CGVs em termos não apenas de quantidade, mas também de qualidade dos empregos gerados na economia.

A outra problemática que ficou em evidência com as cadeias globais de valor é o fato de que o comércio tem se tornado cada vez mais intrarregional, fragilizando assim o princípio de que o comércio tem um caráter mais global, com o predomínio do livre comércio beneficiando de forma mais equitativa todas as nações. Esse fato é empiricamente comprovado em World trade statistical review, da Organização Mundial do Comércio (OMC), onde se afirma que o comércio internacional é predominantemente intrarregional, ou seja, as principais relações comerciais acontecem entre os países da 


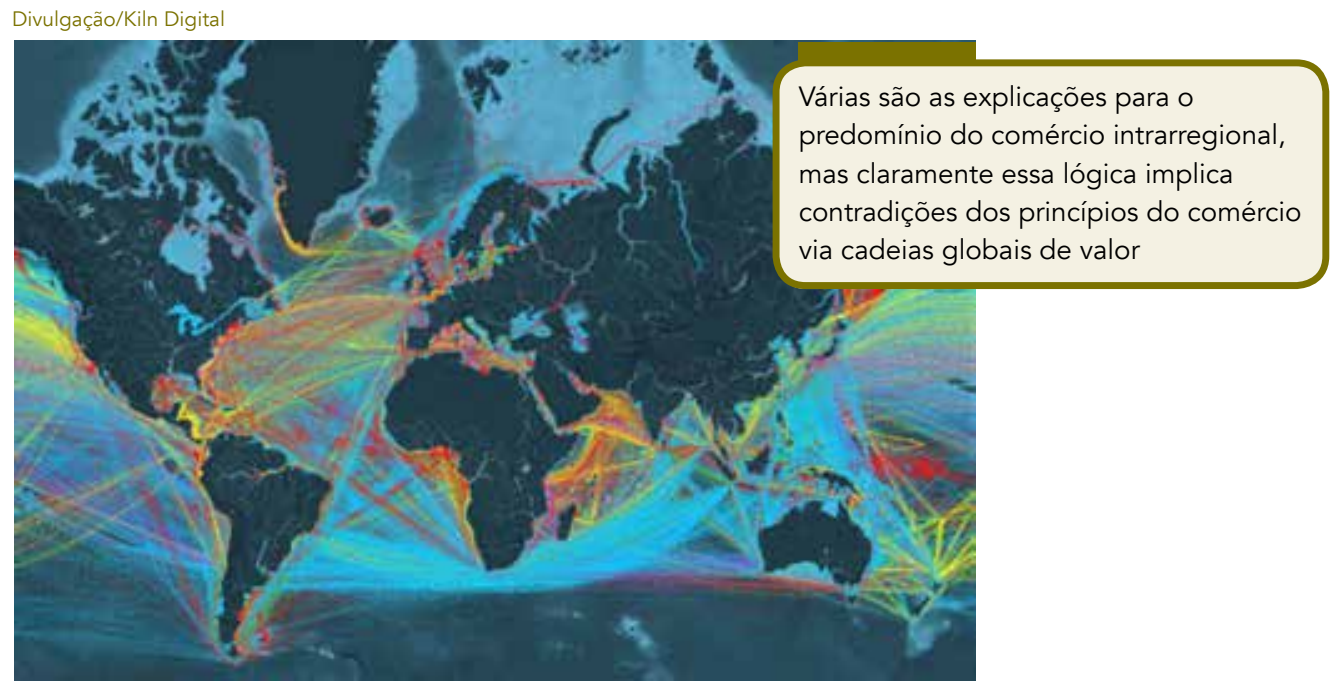

mesma região e/ou blocos econômicos (WTO, 20I9). De acordo com esse relatório, em $2017,70 \%$ do comércio da União Europeia ${ }^{3}$ era feito entre os próprios países da região. Na Asean, esse indicador era de 67\%; no Nafta, de 50\%; e no Mercosul, de 20\%.

Várias são as explicações para o predomínio do comércio intrarregional, mas claramente essa lógica implica contradições dos princípios do comércio via cadeias globais de valor, principalmente por se acreditar que uma das suas principais decorrências seria o aprofundamento das relações comerciais entre as nações da economia global, e não apenas regional.

Thorstensen, Ferraz e Gutierre (20I4) mostram que a aproximação geográfica importa para as CGVs, pois a distância é uma variável considerável para o processo de integração na fragmentação internacional da produção e nas cadeias globais de valor. As CGVs têm em sua dinâmica desafios e riscos, tais como: maior integração e maior desagregação; maior interdependência entre as empresas e entre as nações desenvolvidas e em desenvolvimento; um repensar sobre as políticas desenvolvidas pelos governos, particularmente das nações marginalizadas do processo de integração às redes de produção global, como as da região da África e da América Latina e Caribe, cujos desafios aparentam ser ainda maiores em razão do fator regional, que parece se apresentar como uma grande barreira, impedindo-os de realizar uma integração mais profunda com os grandes blocos regionais que comandam as CGVs.

Uma variável importante para entender as assimetrias é que as CGVs estão associadas à trajetória dos grandes fluxos de comércio de valor agregado que dominam a economia mundial e ocorrem no entorno das principais economias, que são os hubs regionais como EUA, Alemanha e Japão. Por exemplo, Baldwin (2020) mostra que o

3 A União Europeia (UE) é composta por 27 Estados-membros independentes situados principalmente na Europa; a Asean (Associação de Nações do Sudeste Asiático) é uma organização intergovernamental regional com dez países do Sudeste Asiático; o Nafta (North American Free Trade Agreement, ou Tratado Norte-Americano de Livre Comércio) envolve Canadá, México e Estados Unidos; o Mercosul (Mercado Comum do Sul) atualmente é composto por Argentina, Brasil, Paraguai e Uruguai; mais tarde, a Venezuela foi incorporada, mas no momento se encontra suspensa. 
Japão continua a ser um ator importante nas cadeias globais e regionais de valor, mas fica claro que no período recente a China ocupou na região da Ásia o papel principal na cadeia de suprimentos da produção regional, juntamente com a Alemanha na Europa e EUA na América do Norte.

No caso da China e das suas relações comerciais com a Ásia, os dados mais recentes apontam para um fortalecimento do comércio intrarregional, já que a Asean se torna o principal parceiro comercial da China. O total de importações e exportações da China com os dez países-membros da associação aumentou 2\% entre janeiro e junho de 2020, para US\$297,8 bilhões. O bloco representou I4,7\% do comércio total da China no período, ante I4\% em 20I9. A União Europeia, que anteriormente era o maior parceiro comercial da China, reduziu o comércio total com a China em $5 \%$ em 2020, para US \$284,I bilhões. Os EUA, terceiros no ranking, sofreram uma queda de IO\% em meio à deterioração dos laços bilaterais. A UE e os EUA representaram $\mathrm{I} 4 \% \mathrm{e}$ II,5\% do comércio total da China no primeiro semestre, respectivamente (HARADA, 2020). Além do crescimento do comércio entre os países da Ásia, com a liderança da China, o investimento chinês também se amplia na Asean, fortalecendo o comércio intrarregional (SIWEI; JIA, 2020).

Em meio aos boicotes cada vez mais rigorosos sobre acordos de aquisição de alta tecnologia por reguladores europeus e estadunidenses, as empresas chinesas estão recorrendo a países da Iniciativa do Cinturão e Rota para aquisições internacionais. De acordo com Alan Wang, sócio do escritório de advocacia Freshfields Bruckhaus Deringer, os acordos internacionais na Europa e nos EUA com empresas chinesas diminuíram no primeiro semestre de 2020, enquanto o investimento nos países do Sudeste Asiático aumentou. Os investidores chineses fizeram investimentos diretos produtivos em 159 países e regiões, totalizando US\$ 5I,5 bilhões no primeiro semestre de 2020, uma queda de 0,7\% em relação ao ano anterior, segundo dados do Ministério do Comércio. Por outro lado, o investimento em países e regiões na Iniciativa do Cinturão e Rota da Ásia aumentou quase 20\%, para US\$ 8,12 bilhões. A iniciativa é uma estratégia global de desenvolvimento de infraestrutura adotada pela China em 2013 para investir em quase 70 países e organizações internacionais. Os investimentos no primeiro semestre nos dez integrantes da Asean cresceram 53,1\%, para US\$ 6,23 bilhões (SIWEI; JIA, 2020).

Esse fato reforça a dinâmica marcadamente regional das cadeias globais de valor. Baldwin (2013) reconhece que as cadeias de fornecimento globais não são globais, mas sim fortemente regionais. Ele denominou esses blocos regionais de Factory North America, Factory Europe e Factory Asia. Na primeira, o país hub são os EUA, que por intermédio de suas empresas governam as redes de cadeias industriais, muitas delas terceirizadas para o México e Canadá. A Factory Europe tem como hub a Alemanha, que terceiriza a produção para os países pobres de boa parte do Leste Europeu. A Factory Asia é governada pelas empresas japonesas de tecnologia, que se espalharam em forma de rede de produção pelo Leste e Sudeste da Ásia, mas com a China assu- 
mindo maior papel de protagonismo na região na rede intrarregional de produção e de comércio da Ásia (BALDWIN, 20I3; GEREFFI; HUMPHREY; STURGEON, 2005).

A lógica do comércio intrarregional pode ser uma condição vantajosa para integração de determinados países, mas pode ser também uma grande barreira à inserção e upgrading nas cadeias globais para outros países, pois a situação regional limita quem participa das redes produtivas em torno das empresas-líderes pertencentes aos países $h u b s$, ou seja, as empresas-líderes dos países centrais que governam as cadeias globais tendem a terceirizar as etapas de produção para os demais países situados no entorno dos hubs, fortalecendo as relações intrarregionais. Os fatores que propiciam a aproximação regional vão desde as economias de escala, passando pela complementaridade industrial, a facilidade de coordenação da produção e o tamanho de mercado, até as semelhanças culturais.

Os indicadores parecem apontar, portanto, para o fato de que as duas características, abordadas aqui, que têm marcado o comércio internacional - assimetrias entre as nações e predomínio do comércio intrarregional - têm relações muito estreitas, pois, para que o comércio intrarregional aconteça, os países precisam pertencer ao entorno de um país central, com suas empresas transnacionais que exportam e importam peças e partes de bens intermediários, estabelecendo negociações. Se considerarmos os indicadores, identificamos que os países que mais lograram benefícios com a inserção nas CGVs foram justamente os países que pertencem às regiões que apresentam maior percentual de comércio intrarregional, como Ásia e Europa, assim como os EUA. Por outro lado, predomina um menor envolvimento da América Latina, onde os países apresentam baixa participação do comércio intrarregional, consolidando sua posição marginal nas CGVs.

Gereffi (I999) afirma que o comércio dentro das regiões envolve a mudança dos fluxos comerciais bilaterais, assimétricos e inter-regionais para uma divisão intrarregional mais desenvolvida do trabalho, incorporando todas as fases da cadeia de commodities a partir do fornecimento de matérias-primas, através da produção, distribuição e consumo. Essa característica acaba beneficiando os países das próprias regiões e pode estar associada às estruturas produtivas mais avançadas de cada país; ou seja, a Ásia e a União Europeia, por terem estruturas produtivas mais avançadas, densas, diversificadas e inseridas em níveis tecnológicos mais elevados, têm maior facilidade de aprofundar as relações comerciais entre os próprios países, enquanto as nações periféricas, com estruturas produtivas mais frágeis, tendem a não ter condições de fomentar o comércio intrarregional (GEREFFI, I999, p. 5I-52).

Independentemente dos motivos e razões que levam a persistir a relação assimétrica entre as nações e o predomínio do comércio intrarregional, esses acontecimentos deixam em evidência que a crença de que o princípio das cadeias globais de valor mudaria a dinâmica da economia internacional, beneficiando de forma mais equitativa todas as nações, parece ser uma crença exagerada e que pode ser um dos motivos que proporcionaram os questionamentos sobre a relevância de aderir à lógica de fragmentação produtiva. 


\section{INDÍCIOS DO ENFRAQUECIMENTO DAS CADEIAS GLOBAIS DE VALOR ANTERIOR À CRISE GERADA PELA COVID-19}

A crise de 2008-2009 na economia mundial levou muitos países a adotarem medidas de conteúdo local com a finalidade de fortalecer seu mercado interno para superar a crise econômica. Após a crise, um caso emblemático de discurso contrário à globalização foi de Donald Trump, em sua campanha eleitoral nos EUA em 20I6, com a promessa de obrigar as empresas estadunidenses a voltarem para os EUA, estimulando a geração de empregos no país. Esse discurso "nacionalista" se dá em um novo ambiente da organização mundial da produção, no contexto das discussões sobre as cadeias globais de valor. O Peterson Institute for International Economics (PIIE) registrou um grande aumento de políticas domésticas industriais e de medidas de conteúdo local depois da crise financeira internacional de 2008 (HUFBAUER et al., 20I3; STONE; MESSENT; FLAIG, 20I5). O surgimento dessas medidas já apontava para o questionamento sobre a dinâmica do comércio internacional com o predomínio da fragmentação produtiva, principalmente pelo discurso nacionalista de defesa dos interesses nacionais, em particular para a recuperação do emprego.

Analistas como Cattaneo, Gereffi e Staritz (20I0) afirmavam que era muito precipitado acreditar em um rompimento com o processo de globalização e o das CGVs, pois ambos continuam e continuarão a existir depois da crise e se estruturariam ainda mais. Para esses autores, a crise econômica e financeira de 2008-09 não foi capaz de reverter a tendência do fenômeno da globalização. As CGVs mostraram-se resilientes e emergiram como uma característica estrutural de longo prazo da economia mundial.

Entretanto, mudanças importantes na produção e na demanda global ocorreram e a crise acelerou as tendências preexistentes. Essa dinâmica de mudanças é observada pela OCDE, que em estudos recentes tem observado evidências de que a fragmentação internacional da produção tem perdido impulso, principalmente em decorrência do crescimento da importância das tecnologias da Quarta Revolução Industrial (como, por exemplo, TI, robótica, inteligência artificial, automação, $3 \mathrm{D}$ e digitalização), com possível e significativo redesenho das características da economia global e impactos disruptivos nas cadeias globais de valor (OECD, 2017).

Canuto (20I7) afirma que em período recente a economia internacional estava dando sinais de desaceleração da produção e comercialização pelas CGVs. O curioso é que, segundo o autor, esse acontecimento se dá pelos mesmos motivos que promoveram a ascensão dessa forma de divisão internacional do trabalho, isto é, os mesmos progressos tecnológicos que promoveram a ascensão dessa forma de divisão internacional do trabalho podem também ser considerados os responsáveis por promover a sua desaceleração. Por exemplo, de acordo com o autor, as vantagens locacionais baseadas nas vantagens de custos que combinaram salários mais baixos dos países em desenvolvimento ao uso de tecnologias avançadas que foram essenciais para promover a fragmentação vertical da produção, com as reduções das 
barreiras comerciais, agora dão lugar à disponibilidade local de ativos intangíveis complementares, com os requisitos locais de infraestrutura, treinamento trabalhista e solidez de ambientes de negócio abrindo espaço para a horizontalização da produção, pois o princípio da personalização dos produtos vem aumentando a relevância da proximidade com os mercados em relação aos custos de produção com o trabalho.

Outro motivo apontado por Canuto (20I7) para o enfraquecimento do comércio é a dinâmica da China, principalmente considerando o seu peso na economia mundial e sua tendência recente à substituição de importações. Uma das principais estratégias da China para se fortalecer no comércio mundial é associar suas altas taxas de crescimento econômico com estruturas produtivas mais densas e diversificadas, com políticas de promoção e reestruturação da sua produção que apontam a transição para um modelo de crescimento menos dependente do investimento e da exportação e mais baseado no consumo, com a finalidade de consolidar a sua inserção nas CGVs e subir a estágios das cadeias que agreguem mais valor, principalmente fortalecendo suas relações intrarregionais.

Essa estratégia da China está vinculada ao que se convencionou chamar de "Silk Road", que vai além de um mecanismo de promover maior integração entre seus principais parceiros comerciais, pois também envolve uma lógica promovida pela China de condicionar o desempenho dos mercados emergentes e das economias em desenvolvimento, integrando atividades de mais alto valor agregado na cadeia, com a China permitindo que atividades de fabricação de mão de obra com baixa intensidade aconteçam em outros países, podendo abrir oportunidades para países atualmente dotados de mão de obra barata e abundante. Isso acaba resultando em uma redução do volume de comércio global e, ao mesmo tempo, fortalecendo a lógica assimétrica da economia internacional, como já apontado anteriormente.

Outra dimensão que Canuto (20I7) aponta como motivo para a redução do comércio mundial pela lógica das cadeias globais de valor são as mudanças tecnológicas nas áreas de inteligência artificial e robótica, associadas a uma maior elasticidade-renda da demanda por serviços sofisticados nas economias avançadas, que estão promovendo uma onda de "desmaterialização" da demanda por produtos padronizados, já que o uso de menores quantidades de materiais na provisão de bens sugere uma reversão parcial do offshoring, um crescimento mais lento para as exportações típicas e uma remodelação das CGVs.

Timmer et al. (20I6) também identificaram uma tendência de desaceleração do comércio internacional observada desde 20II, decorrente de uma redução geral na atividade econômica global. De acordo com os autores, quando se analisam as importações de bens e serviços como proporção do PIB mundial entre 2008 e 2009, identifica-se uma redução significativa das importações em decorrência da crise global e uma retomada do crescimento após esse período. Entretanto, após 20II as importações voltam a cair sutilmente e esse comportamento se prolonga, apontando para 
indícios de que a relação entre comércio e crescimento do PIB está passando por uma mudança fundamental.

Para os autores, duas possíveis variáveis explicam esse cenário: a primeira está relacionada com as mudanças na composição da demanda final - que contém tanto consumo como demanda de investimento - , a qual mostrou que a recessão econômica global e suas consequências afetaram várias categorias de demanda final em diferentes graus e a propensão a realizar gastos em investimentos e bens de consumo. Essa primeira dimensão pode estar associada à dinâmica cíclica da economia internacional, mas também pode ser resultado de estratégias de políticas de internalização das cadeias produtivas nacionais. A segunda variável seria resultante do declínio das cadeias de valor globais, particularmente com as mudanças na estrutura de produção internas de alguns países e a robotização — com a ascensão da indústria 4.0 - , que elevou a capacidade de produção local.

Um ponto em comum na literatura sobre comércio internacional e cadeias globais de valor é a constatação de que a nova onda de inovação tecnológica, conhecida como "indústria 4.0", já está tendo impactos no comércio, e isso tende a se intensificar.

Segundo Hermann, Pentek e Otto (20I5), há evidências de que a Quarta Revolução Industrial pode ser considerada, de certa forma, como resultado de uma estratégia dos países desenvolvidos, que articula planos empresariais e ações públicas de suporte, para combater as ameaças ao protagonismo ocidental advindas do crescimento industrial no Oriente, em especial a China. As mudanças promovidas pela indústria 4.0 apresentariam um potencial promissor para superar o modelo de produção em larga escala e baixo custo nos países emergentes, assim como os seus efeitos nos fluxos de comércio (os déficits comerciais de muitos países ocidentais com a China, por exemplo) e, ao menos parcialmente, na desindustrialização.

A United Nations Industrial Development Organization considera que a mudança de paradigma atual vai além da indústria 4.o (UNIDO, 20I6). A Quarta Revolução Industrial seria caracterizada por uma fusão de tecnologias que estreita as linhas entre as esferas física, digital e biológica na estrutura produtiva. Diante dessas transformações, segundo a Unido, a questão crucial é se a combinação e a aplicação generalizada dessas tecnologias também resultariam em um efeito líquido positivo para as economias e sociedades em geral.

A ascensão das tecnologias da indústria 4.0 e a produção industrial em $3 \mathrm{D}$ têm um grande potencial para remodelar as CGVs, alterando sua extensão geográfica e densidade. Com essa tecnologia, componentes físicos podem ser produzidos perto do local de montagem no país de consumo, reduzindo ainda mais o número de fornecedores.

O debate que antecede a crise atual do capitalismo, com a pandemia de covid-I9, deixa nítido que o comércio mundial via cadeias globais de valor já apontava para um processo de arrefecimento, principalmente como resultado das contradições que estão inseridas na economia internacional com as assimetrias existentes e com a 


\section{Tudo indica que a crise gerada} pela covid-19 tem acentuado esse movimento de necessidade de fortalecimento de estruturas produtivas internas ao redor do mundo

intensificação do comércio intrarregional, cenário este que pode ter contribuído para que muitos países tenham adotado políticas de fortalecimento de cadeias produtivas internas, reduzindo, portanto, a sua fragmentação produtiva e impactando no volume do comércio. Com a ascensão de um novo paradigma tecnológico com a indústria 4.o, há sinais de que o processo de desaceleração das cadeias globais de valor vem se intensificando. Tudo indica que a crise gerada pela covid-I9 tem acentuado esse movimento de necessidade de fortalecimento de estruturas produtivas internas ao redor do mundo.

\section{A CRISE ORIGINADA PELA COVID-19 E SEUS IMPACTOS NO COMÉRCIO MUNDIAL}

A Unctad (Conferência das Nações Unidas sobre Comércio e Desenvolvimento) reconhece claramente que o comércio via cadeias globais de valor vem perdendo força desde a crise de 2008 , tendência que se acelera acentuadamente com a crise deflagrada pela pandemia (UNCTAD, 2020).A Unctad afirma que o sistema global de produção internacional está passando por uma tempestade perfeita com a crise causada pela pandemia, com desafios decorrentes da nova revolução industrial, o crescente nacionalismo econômico e o imperativo da sustentabilidade.

Para a Unctad (2020), existem no mundo hoje megatendências que impulsionam a transformação da produção internacional. Essas megatendências são agrupadas em três temas principais:

I) Novas tecnologias com uma nova revolução industrial - a aplicação de novas tecnologias nas cadeias produtivas das empresas multinacionais globais tem consequências de longo alcance para a configuração das redes internacionais de produção. Basicamente, essa nova revolução industrial é o tema já abordado na seção 4 deste artigo, tratando das tecnologias digitais que resultam em processos de produção mais integrados, redução nos custos de governança e transação, coordenação mais eficaz de cadeias de valor complexas e melhor acesso ascendente às CGVs para fornecedores de pequenas e médias empresas (PMEs). O ponto crítico é o crescente processo de automação, com disponibilidade de robôs industriais mais baratos, que tem o potencial de reverter a tendência da fragmentação produtiva, reduzindo drasti- 
camente a vantagem competitiva dos centros de fabricação de baixo custo nos países em desenvolvimento. Esse efeito, aliado ao aumento do custo da mão de obra nos mercados emergentes e ao aumento dos riscos geopolíticos, pode desencadear uma onda de remanejamento das atividades manufatureiras.

2) Governança econômica global — há uma tendência para a crise de cooperação multilateral, com o fortalecimento de soluções regionais e bilaterais, assim como o crescimento de medidas de protecionismo. Isso é agravado pela competição sistêmica entre as potências econômicas, bem como por uma mudança geral na formulação da política econômica nacional em muitos países no sentido de mais regulamentação e intervenção. Ou seja, claramente há um movimento de abandono na crença em uma abordagem econômica laissez-faire em muitas economias, com ascensão da defesa de um papel cada vez mais intervencionista do Estado. A implementação de políticas industriais formais e de medidas de políticas individuais destinadas a estimular os setores industriais acelerou-se significativamente. Na última década, pelo menos IIo países emitiram declarações de política industrial ou estruturas de políticas explícitas para o desenvolvimento industrial. Os governos estão usando políticas industriais direcionadas não apenas para o desenvolvimento econômico e a criação de empregos, mas também para responder a uma miríade de desafios contemporâneos, como o desenvolvimento regional e a redução da pobreza, participando da revolução tecnológica e atingindo as metas de sustentabilidade. Nesse cenário, as políticas industriais tornaram-se comuns não apenas entre os países em desenvolvimento, mas também entre os desenvolvidos. Políticas para impulsionar o crescimento da produtividade em setores essenciais para o desenvolvimento industrial — principalmente manufatura, mas também serviços auxiliares e infraestrutura de apoio - são amplamente consideradas indispensáveis para gerar crescimento econômico e empregos. Os países em desenvolvimento são frequentemente motivados por preocupações com a desindustrialização prematura. Em contrapartida, os países desenvolvidos estão adotando medidas destinadas a reconstruir sua base manufatureira (incentivos, subsídios, investimento público em manufatura avançada para aumentar a capacidade produtiva interna) e a promover seu reposicionamento estratégico em áreas de tecnologia 
avançada. Além disso, as políticas industriais estão cada vez mais visando a setores considerados estratégicos não apenas para a criação de empregos, crescimento econômico de longo prazo e perspectivas de desenvolvimento, mas também por razões de segurança nacional. A importância estratégica das indústrias farmacêutica e de equipamentos médicos, por exemplo, com sua dependência de pesquisa e inovação de ponta, pode fazer com que cada vez mais países implementem políticas para desenvolver a capacidade produtiva nacional.

3) Desenvolvimento sustentável - o mundo passa pela implementação de um amplo leque de medidas de sustentabilidade, incluindo medidas de adaptação às mudanças climáticas, e de mitigação destas, nas operações globais das empresas multinacionais; velocidades diferenciadas na adoção e implementação de regras, regulamentos e práticas voltados para a sustentabilidade terão implicações importantes para as redes de produção internacionais. De forma gradual, o aumento da regulamentação, a pressão da sociedade civil e as melhorias no monitoramento do impacto social e ambiental influenciaram a forma como as empresas multinacionais - com forte atuação nas cadeias globais de valor - operam no exterior e afetaram, em certa medida, as configurações de produção internacionais. O impacto, até o momento, tem sido amplamente limitado à dimensão de governança das configurações de produção internacionais - e menor quanto ao grau de fragmentação e distribuição geográfica.

Para a Unctad (2020) a tendência é que o conjunto das medidas contempladas nessas três megatendências se aprofunde, pois a crise atual gerou amplas paralisações de produção e graves interrupções na cadeia de abastecimento na maioria dos setores, fechamento de indústrias inteiras e choques de demanda sem precedentes em quase todas as economias, colocando em risco questões de soberania nacional. No longo prazo, a necessidade de as empresas multinacionais criarem cadeias de abastecimento mais resilientes, combinada com uma maior pressão dos governos e do público para aumentar a autonomia nacional ou regional, especialmente de bens e serviços essenciais (por exemplo, relacionados a cuidados de saúde), terão efeitos duradouros nas redes globais de produção, ou seja, podem consolidar uma nova dinâmica do comércio internacional.

Como a própria Unctad reconhece e conforme já apontado neste artigo, esse movimento não teve início com a crise causada pela covid-ı, pois mudanças e dinâmicas das políticas industriais pelo mundo já vinham ganhando força nos últimos anos, principalmente a partir da crise de 2008-2009, com vários países adotando políticas industriais de forma estratégica. Medeiros (2019) mostra que nos EUA a política industrial sempre esteve concentrada no Departamento de Defesa (Darpa), no ministério e institutos de saúde (National Institutes of Health) e no Ministério de Energia (Arpa-E), principalmente por meio de recursos, projetos e laboratórios financiados pelo governo. Ainda no caso dos EUA, o melhor exemplo de políticas industriais é o complexo acadêmico-industrial-militar, o qual é responsável pela criação de novos 
setores e atividades, e sempre se fez presente a busca por alternativas energéticas e tecnologias verdes, ampliando assim esforços públicos de inovação.

A Alemanha vem sendo apontada como o país que deu o pontapé inicial para os grandes projetos de políticas industriais para o avanço da indústria 4.o. O país já vem adotando uma abrangente política industrial, com a finalidade de criar fábricas inteligentes por meio de sistemas cyber physical, integrando informação (big data) com robôs, internet das coisas e manufatura aditiva, de forma a concentrar mais e mais sua especialização produtiva na capacidade de inovação.

Quando há o debate em torno dos motivos para as assimetrias entre as nações nas formas de inserção nas cadeias globais de valor, particularmente considerando as experiências dos países asiáticos e da América Latina, Cimoli, Dosi e Stiglitz (2008) afirmam que há uma grande diferença nos processos de conhecimento e acumulação de competências ou aptidões entre as duas regiões. Para os autores, houve um conjunto de políticas industriais agressivas na região asiática que permitiram elevar as capacidades e o desenvolvimento industrial, moldando o padrão de produção e a inserção comercial voltada para as indústrias da fronteira tecnológica e produtos de alta elasticidade-renda. Enquanto isso, a América Latina foi menos incisiva nas suas políticas, com baixos ganhos em termos de aprendizagem e capacitações, recuando para as indústrias distantes da fronteira, intensivas em recursos naturais e de baixa elasticidade-renda.

Sobre as experiências dos países asiáticos em manter de forma contínua políticas industriais, vários acontecimentos recentes têm deixado mais evidente como esses países têm interpretado o cenário da covid-ı e a relevância da política industrial.

Um fato emblemático do enfraquecimento dessa lógica e da necessidade de retomada de fortalecimento das cadeias produtivas internas, com maior densidade e diversificação de cadeias produtivas nacionais como elementos estratégicos no cenário geopolítico internacional e para a soberania nacional, foi uma entrevista do atual primeiro-ministro do Japão Yoshihide Suga, o qual afirmou que o maior ensinamento da crise atual é que a fragmentação excessiva de cadeias de produção no Japão mostrou como o país estava vulnerável a decisões externas, em particular da China. Um exemplo citado pelo primeiro-ministro foi o fato de que uma montadora japonesa não conseguiu adquirir peças e teve de deixar uma fábrica parada. Yoshihide Suga defendeu, explicitamente, a ideia de que o país precisa acabar com a forte dependência e "trazer a produção de volta para o Japão" (SHIGETA, 2020).

Nesse sentido, o Japão lançou um programa de subsídios de 220 bilhões de ienes (US\$2,08 bilhões) para encorajar as empresas japonesas a levarem suas fábricas de volta para o país, e alocou 23,5 bilhões de ienes adicionais para financiar a movimentação da produção para o Sudeste Asiático. Até julho deste ano, foi aprovada a concessão de subsídios para quase 90 empresas japonesas,, enquanto mais de I.60o empresas solicitaram os fundos (LI; TING-FANG, 2020). 
A Índia, mesmo com as reformas liberalizantes dos anos I990, também vem dando sinais de fortalecimento das suas cadeias produtivas internas. Com essa crise, o primeiro-ministro da Índia, Narendra Modi, anunciou um pacote de estímulo de US\$ 265 bilhões - cerca de I0\% do PIB - para atrair investimentos externos e desenvolver as estruturas produtivas do país, principalmente fortalecendo cadeias produtivas nacionais para enfrentar a concorrência chinesa (CAMPOS, 2020).

$\mathrm{Na}$ Coreia do Sul, o programa de reestruturação produtiva por meio da centralização dos chaebols, introduzido a partir da crise de 1997, retomou em novas bases a política industrial. Além do mais, o "New Deal coreano" (HYUNJUNG, 2020), implementado para enfrentar a crise causada pela covid-I9, tem como principal elemento o investimento em setores de inovação, setores relacionados à sustentabilidade e proteção e geração de empregos, com a finalidade de fortalecer a estrutura produtiva do país e também enfrentar a concorrência no mundo, em particular a da China.

$\mathrm{O}$ "New Deal da Coreia" prevê investimento em inovação e defesa do emprego, com um montante de mais de I6o trilhões de won (US\$ 132,67 bilhões) e criação de I,9 milhão de empregos nos próximos cinco anos. Além do mais, o "New Deal" também envolve um amplo processo de investimento em setores estratégicos, em uma aliança entre empresas e governo, com ampla oferta de empréstimos. Essa aliança é resultado de um processo histórico de estratégia de desenvolvimento do país, com o papel de protagonismo que as grandes empresas sul-coreanas, as chamadas chaebols, sempre tiveram.

Os êxitos e propostas do "New Deal da Coreia" têm chamado a atenção das instituições internacionais, as quais têm elogiado a estratégia do país em combater a crise mediante políticas industriais que têm como objetivo promover o desenvolvimento de setores industriais intensivos em tecnologia associado à sustentabilidade, além da proteção ao emprego. A OCDE afirma que, com esse programa, a Coreia se coloca como uma estrela em ascensão na economia internacional, mantendo-se como um dos países que têm uma das principais empresas digitais e de tecnologias no mundo - a Samsung - , com um grande e crescente setor de tecnologia da informação, excelente infraestrutura digital, acesso quase generalizado à internet de alta velocidade e a primeira introdução nacional de $5 \mathrm{G}$ em todo o mundo (OECD ILIBRARY, 2020).

Em Taiwan, as políticas industriais, bem como seus Estados desenvolvimentistas, não foram desconstruídas nos anos 1990, suas instituições e mecanismos persistiram e vêm promovendo a modernização tecnológica. Diante da crise criada pela pandemia e dos acirramentos dos conflitos entre EUA e China, Taiwan tem aproveitado sua posição-chave, pois suas empresas de tecnologia - a Taiwan Semiconductor Manufacturing Co. (TSMC), maior fabricante de chips contratados do mundo, e a Foxconn Technology Group, anteriormente conhecida como Hon Hai Precision Industry, maior fabricante contratada de eletrônicos do mundo - , vendem para a China e para os EUA. Como é um país estratégico, otimiza esse cenário geopolítico 
para adotar políticas de fortalecimento de cadeias produtivas internas e nacionais, realizando uma campanha de "transferência da produção de volta para Taiwan", com incentivos fiscais especiais e taxas de juros para empréstimos, desde o final de 20I8 (SHIGETA, 2020).

A "guerra comercial" entre China e EUA talvez seja o melhor exemplo da maior necessidade de domínio tecnológico e de fortalecimento das cadeias produtivas nacionais como elementos essenciais para a soberania nacional. Nas eleições atuais, tanto Donald Trump (Partido Republicano) quanto Joe Biden (Partido Democrata) defendem uma política de atração das empresas estadunidenses para o país, a fim de fortalecer a cadeia produtiva nacional e também para gerar mais empregos no próprio país.

Além de o governo estadunidense defender uma política de fortalecimento das cadeias produtivas internas e atrair as empresas estadunidenses para o país, há também a imposição de políticas de sanção contra a China, com a finalidade de impedir o desenvolvimento tecnológico do seu principal rival na economia internacional. Tudo começou em 20I6, com as sanções impostas pelos EUA contra a empresa de equipamentos de telecomunicações chinesa ZTE (Zhong Xing Telecommunication Equipment Company Limited), e tornou-se cada vez mais sério à medida que Washington aumentava a pressão sobre outras empresas chinesas, com o argumento de que elas ameaçavam a segurança nacional dos EUA. No espaço de um ano, Washington revisou suas regras de controle de exportação três vezes para atingir a Huawei $^{4}$ - mudanças essas que afetaram os fornecedores estadunidenses e não estadunidenses de microchips e placas de circuitos avançados (LI; TING-FANG, 2020).

Como resposta, na China os gastos em pesquisa e desenvolvimento (P\&D), os investimentos em parques tecnológicos, os programas de compras e de financiamento de governo voltados para indústrias de alta tecnologia, tanto no setor de tecnologia da informação e da comunicação, de biotecnologia e de energia quanto no programa espacial e militar, reafirmam a estratégia do país em lograr estruturas produtivas mais densas e diversificadas, dando ao país maior autonomia em sua trajetória de desenvolvimento.

A China divulgou que nos próximos planos quinquenais do país haverá prioridade para a chamada "dual circulation strategy" (WHEATLEY, 2020), com foco em inovação e tecnologia, como nova estratégia para enfrentar o duelo econômico contra os EUA. Essa nova estratégia tem duas linhas de ação: a) fortalecer o mercado interno; b) ampliar o investimento tecnológico. De acordo com as previsões para os próximos planos quinquenais, a China vai priorizar o aumento do investimento em inovação. Por exemplo, a parcela de P\&D no PIB, de 2,5\% em 2020, deve aumentar para cerca de $3 \%$ em 2025, e aumentarão ainda mais os gastos em educação e treinamento vocacio-

4 Empresas chinesas como a Huawei e a ZTE estão perdendo o acesso a microchips e placas de circuitos avançados diante dos boicotes dos EUA. As últimas regras anunciadas, em julho de 2020, pelo Departamento de Comércio proibiram efetivamente qualquer empresa, em qualquer lugar do mundo, de fornecer chips para a Huawei ou qualquer uma de suas subsidiárias sem primeiro obter uma licença do governo dos EUA (GILL, 2020a). 


\section{A “guerra comercial” entre China e EUA talvez seja o melhor exemplo da maior necessidade de domínio tecnológico e de fortalecimento das cadeias produtivas nacionais como elementos essenciais para a soberania nacional}

nal. A digitalização é uma área chave em que a China provavelmente tentará manter sua liderança, com o governo apoiando ainda mais a digitalização.

Do ponto de vista da sustentabilidade, com sua ambição persistente, de longo prazo, em desenvolver a economia verde, a China também irá estabelecer um padrão mais alto de proteção ambiental e emissão de poluição no novo plano de cinco anos. Isso inclui I8\% para a participação de energia não fóssil no consumo total de energia (versus $15,3 \%$ em 20I9, e meta de $15 \%$ definida para 2020), maior redução do uso de energia por unidade do PIB e das emissões de dióxido de carbono e dióxido de enxofre. A lógica entre sustentabilidade e desenvolvimento econômico como elemento estratégico ficou clara no discurso de Xi Jinping na Assembleia Geral da ONU, abordando as medidas vigorosas para controlar a emissão de poluentes e alcançar a neutralidade de carbono antes de 2060 (TOOZE, 2020).

Essas estratégias anunciadas ou implementadas na China para enfrentar o cenário de acirramento dos conflitos com os EUA convergem para a ideia de promover o rejuvenescimento da nação chinesa, com o presidente Xi Jinping anunciando o plano de controle do governo para orientar as empresas do setor privado a se inserirem em uma "nova era" da economia mundial, deixando claro que o país vai fortalecer as suas estruturas produtivas internas para lograr autonomia tecnológica e consolidar o potencial do seu mercado interno (GILL, 2020).

As evidências mostram que, embora muitos tenham defendido a dinâmica das cadeias globais de valor como uma janela de oportunidade, a integração e a ascensão das economias em desenvolvimento nas redes de produção mundial em várias indústrias não foram automáticas, mas resultado de estruturas produtivas já construídas historicamente, com uma atualização das estratégias de políticas industriais, ou seja, esses países nunca abdicaram da política industrial como elemento essencial para o desenvolvimento.

Sturgeon et al. (2013) reconhecem que as estratégias nacionais de políticas industriais estavam associadas a um mecanismo de inserção e upgrading no padrão das CGVs, em que a especialização nos estágios produtivos das cadeias produtivas globais e regionais tem interações entre o global, regional, nacional e o local. 
Após a crise de 2008-2009 e a crise atual, resultado da pandemia de covid-I9, os países têm acelerado a estratégia de implementar um amplo leque de políticas para fortalecer cadeias produtivas internas, com forte potencial de reverter a tendência da fragmentação produtiva, principalmente após os países experimentarem os conflitos geopolíticos recentes, assim como ter ficado em evidência o risco de um país ficar vulnerável na economia internacional a decisões de outros países, colocando-se sua soberania e interesses nacionais em jogo.

\section{CONCLUSÃO}

Ainda é muito cedo para fazer afirmações mais categóricas, mas, desde a crise de 2008, há uma tendência de enfraquecimento da lógica das cadeias globais de valor e uma ascensão de políticas que têm o objetivo de fortalecimento de cadeias produtivas nacionais, principalmente com a finalidade de garantir a soberania nacional. Esse cenário tem se acentuado com a crise provocada pela covid-I9, e tudo indica que os países que não tiverem estratégias e políticas para fortalecer suas estruturas industriais internas e nacionais correm sérios riscos de ficar à margem das fronteiras produtivas e tecnológicas..

Como já discutido, uma das tendências é o delineamento de uma nova fronteira tecnológica e nova dinâmica da política industrial, que vem se acentuando com a crise atual. Nesse sentido, considerando que muitos países, como o Brasil, ficaram presos à chamada "armadilha da renda média" ou à sua trajetória de desenvolvimento, principalmente do ponto de vista de estruturas produtivas, Perez e Soete (I988) afirmam que paradigmas tecnológicos emergentes podem servir como uma janela de oportunidade para os países retardatários avançarem para novas tecnologias. Lee e Malerba (20I7) afirmam que o conceito de janelas de oportunidade foi usado pela primeira vez por Perez e Soete (1988) para se referir ao papel do surgimento de novos paradigmas tecnoeconômicos que pudessem gerar o avanço dos países retardatários, que se aproveitariam de um novo paradigma para superar sua condição de industrialização tardia e competir com países pioneiros.

Por exemplo, de acordo com Lee e Malerba (20I7), a substituição da tecnologia analógica pela tecnologia digital desde os anos 1990 - Terceira Revolução Industrial - foi uma janela de oportunidade para a Coreia e Taiwan lograrem um catch up relevante, superando barreiras para o avanço em suas respectivas estruturas produtivas. Da mesma forma, podemos considerar que as transformações tecnológicas, com a indústria 4.o, podem ser uma janela de oportunidade para economias retardatárias buscarem estratégias para o catch up. Para isso, são necessárias respostas coordenadas e estratégicas para realizar esses potenciais.

Lee e Malerba (20I7) afirmam que diante do surgimento de "janelas de oportunidades", a resposta de empresas, governos e outros atores do sistema setorial de inovação de um país a essas novas possibilidades é essencial para a maximização 
dessas oportunidades. Para isso, alguns elementos são essenciais, como a construção do processo de aprendizagem, o nível de capacidades, a organização e as estratégias. Além disso, as respostas dos outros atores e dimensões do sistema setorial em um país específico podem desempenhar um papel importante no catch up, principalmente considerando os diversos tipos e níveis de redes, sistema educacional, universidades, organizações financeiras e políticas públicas, entre outras dimensões.

Cimoli, Dosi e Stiglitz (p. 4I-43, 20I8) oferecem um arcabouço importante para a reflexão sobre novas tendências de políticas industriais diante de novas janelas de oportunidades, como o cenário atual proporciona. Para os autores, a experiência histórica mostra uma grande variedade de combinações nacionais e setoriais dos tipos de políticas de aprendizagem e de inovação industrial, em que cinco regularidades sempre estão presentes e são relevantes:

$\mathrm{I}^{\mathrm{a}}$ regularidade - em primeiro lugar, uma regularidade que se mantém desde o século XIX na Europa e nos Estados Unidos até os tempos contemporâneos é a centralidade das instituições públicas, tais como universidades, e das políticas públicas na geração e no estabelecimento de novos paradigmas tecnológicos.

$2^{\mathrm{a}}$ regularidade - os incentivos muitas vezes não bastam. Um papel crucial das políticas é afetar as capacidades dos atores, especialmente no caso mencionado dos novos paradigmas tecnológicos, mas também em todos os casos de catching-up em que nenhuma estrutura de incentivos razoável poderia ser suficiente para motivar os agentes privados a superar grandes defasagens tecnológicas.

$3^{\text {a }}$ regularidade - a disciplina de mercado é útil na medida em que elimina as de baixo desempenho e premia as de alto desempenho dentro de populações específicas de empresas. No entanto, nada garante que os choques seletivos não irão acabar com as populações inteiras, assim eliminando, também, qualquer possibilidade de aprendizagem futura.

$4^{\mathrm{a}}$ regularidade - as políticas, especialmente aquelas voltadas ao catchingup, geralmente enfrentam a necessidade de balancear medidas destinadas à capacitação (e também a proteger a "nascente aprendiz") com mecanismos que contribuam para conter a inércia e o rentismo. Por exemplo, estes são, de fato, um dos principais elementos na antiga experiência latino-americana de substituição de importações, enquanto aquelas são o que falta em muitas políticas mais recentes de "liberalização".

$5^{\text {a }}$ regularidade - historicamente, um bem-sucedido esforço de catching-up em termos de renda per capita e salários é sempre acompanhado de catching-up nos novos e mais dinâmicos paradigmas tecnológicos, independentemente dos padrões iniciais de vantagens comparativas, da especialização e dos sinais gerados pelo mercado. Nossa hipótese é que, ceteris paribus, a necessidade 
estrutural de políticas que afetem também os padrões de sinais econômicos (inclusive preços relativos e rentabilidades relativas), à medida que surgem no mercado internacional, aumentará de acordo com a distância do país em relação à fronteira tecnológica. Isso é o que Amsden provocativamente chamou de políticas de deliberado "erro nos preços". Por outro lado, os mecanismos endógenos do mercado tendem a se comportar de maneira "virtuosa" para os países que estão na fronteira, especialmente no que diz respeito às tecnologias mais novas/mais promissoras. Isso é amplamente confirmado pela experiência histórica: o livre comércio incondicional muitas vezes foi defendido e plenamente explorado somente pelos países líderes em tecnologia e política.

* Doutor em Desenvolvimento Econômico pelo Instituto de Economia da Universidade Estadual de Campinas (IE-Unicamp). Atualmente é professor adjunto, em regime de dedicação exclusiva, da Faculdade de Ciências Econômicas da Universidade Federal da Bahia (FCE-UFBA). É pesquisador visitante do Instituto de Pesquisa em Econômica Aplicada (Ipea). Foi consultor do Inter-American Development Bank (IDB), pesquisador visitante do Korea Institute for International Economic Policy (Kiep) e pesquisador convidado do Russian Institute for Strategic Studies (Riss). Tem experiência nas áreas de economia internacional, organização industrial e economia brasileira, com ênfase em estudos sobre o setor externo e o desenvolvimento industrial do Brasil e da Coreia do Sul.

Texto recebido em outubro de 2020; aprovado em outubro de 2020. 
BALDWIN, Richard. Global supply chains: why they emerged, why they matter, and where they are going. In: ELMS, Deborah K.; LOW, Patrick (Ed.). Global value chains in a changing world. Genebra: WTO, 2013.

BALDWIN, Richard; FREEMAN, Rebecca. Supply chain contagion waves: thinking ahead on manufacturing "contagion and reinfection" from the covid concussion. VoxEU/CEPR, 1 abr. 2020.

BALDWIN, Richard; ROBERT-NICOUD, Frederic. The impact of trade on intraindustry reallocations and aggregate industry productivity: a comment. Cambridge: National Bureau Of Economics Research, 2004.

Trade-in-goods and trade-in-tasks: an integrating framework. Cambridge: National Bureau Of Economics Research, 2010. BAMBER, Penny et al. Global value chains and economic development. In: FREDERICK, Stacy et al. Joint project between GVCC and KIET. DUKE GVC Center, 2017. p. $1-16$.

CAMPOS, Guilherme L. Índia anuncia 10\% do PIB em investimentos para tirar indústrias da China. Conexão Política, 14 maio 2020. Disponível em: <https://conexaopolitica.com.br/ultimas/india-anuncia-10-do-pib-em-investimentos-para-tirar-industrias-da-china/amp/?_twitter_impression=true >. Acesso em: 24 out. 2020.

CANUTO, Otaviano. Overlapping globalizations. Washington, D.C.: The World Bank, 2017.

CARNEIRO, Flávio Lyrio. Fragmentação internacional da produção e cadeias globais de valor. In: OLIVEIRA, Ivan Tiago Machado; CARNEIRO, Flávio Lyrio; SILVA FILHO, Edison Benedito da (Org.). Cadeias globais de valor, políticas públicas e desenvolvimento. Brasília: Ipea, 2017. p. 87-120.

CARNEIRO, Ricardo. Globalização e integração periférica. Campinas: IE-Unicamp, 2007. (Texto para Discussão, n. 126).

CATTANEO, Olivier; GEREFFI, Gary; STARITZ, Cornelia (Ed.). Global value chains in a postcrisis world: a development perspective. Washington, D.C.: The World Bank, 2010.

CIMOLI, Mario; DOSI, Giovanni; STIGLITZ, Joseph. A lógica da política industrial e da inovação. In: CASTRO, Ana Célia; FILGUEIRAS, Fernando (Ed.). Estado no século XXI. Brasília: Enap, 2018.

DELOITTE. Deloitte state of $\mathbf{A l}$ in the enterprise (2nd ed.). Deloitte LLC. Retrieved from www. deloitte.com/insights/stateofai [Google Scholar], 2018.

ESTEVADEORDAL, Antoni; SUOMINEN, Kati; BLYDE, Juan. Are global value chains really global?: policies to accelerate countries access to international production networks. The E15 Iniciative, 2012.

FEENSTRA, Robert C. Integration of trade and disintegration of production in the global economy. The Journal of Economic Perspectives, v. 12, n. 4, p. 31-50, 1998.

GEREFFI, Gary. A global value chain perspective on industrial policy and development in emerging markets. Raleigh: Duke University, 2014.

. International trade and industrial upgrading in the apparel commodity chain. Journal of International Economics, v. 48, n. 1, p. 37-70, 1999.

GEREFFI, Gary; HUMPHREY, John; STURGEON, Timothy. The governance of global value chains. Review of International Political Economy, v. 12, n. 1, p. 78-104, 2005.

GEREFFI, Gary; LUO, Xubei. Risks and opportunities of participation in global value chains. Policy Research Working Paper, n. 6.847, 2014.

GIBBON, Peter; BAIR, Jennifer; PONTE, Stefano. Governing global value chains: an introduction. Economy and Society, v. 37, n. 3, p. 315-338, 2008

GILL, Chris. China's semiconductor firms hit hard by sanctions. Asia Times Financial, Hong Kong, 26 ago. 2020a. Disponível em: <www.asiatimesfinancial.com/china-s-semiconductor-firms-hit-hard-by-sanctions>. Acesso em: 24 out. 2020. 
CCP announces plan to take control of China's private sector. Asia Times Financial, Hong Kong, 17 set. 2020b. Disponível em: <www.asiatimesfinancial.com/ccp-announces-plan-to-take-control-of-chinas-private-sector>. Acesso em: 24 out. 2020.

GROSSMAN, Gene M.; ROSSI-HANSBERG, Esteban. Trading Tasks: A Simple Theory of Offshoring. American Economic Review, American Economic Association, vol. 98(5), pages 1978-97, December, 2008.

HARADA, Issaku. Asean becomes China's top trade partner as supply chain evolves. Nikkei Asia, Tóquio, 15 jul. 2020. Disponível em: <https://asia.nikkei.com/Politics/International-relations/ASEAN-becomes-China-s-top-trade-partner-as-supply-chain-evolves >. Acesso em: 24 out. 2020.

HERMANN, Mario; PENTEK, Tobias; OTTO, Boris. Design principles for industrie 4.0 scenarios: a literature review. Technische Universität Dortmund, 2015.

HYUNJUNG, Bae. Korea's W160tr "New Deal" project aims to create 1.9m jobs by 2025. The Korea Herald, Seul, 14 jul. 2020. Disponível em: <www.koreaherald.com/view.php?ud=20200714000951>. Acesso em: 24 out. 2020.

HUFBAUER, Gary Clyde et al. Local content requirements: a global problem. Peterson Institute for International Economics, 2013.

HUMMELS, David; ISHII, Jun; YI, Kei-Mu. The nature and growth of vertical specialization in world trade. Journal of international Economics, v. 54, n. 1, p. 75-96, 2001.

JONES, Ronald W; KIERZKOWSKI, Henryk. The Role of Services in Production and International Trade: A Theoretical Framework. IN: JONES, Ronald ; KRUEGER, (eds.). The Political Economy of International Trade. Basil Blackwell, Oxford,1990.

KOOPMAN, Robert et al. Give credit where credit is due: tracing value added in global production chains. Hong Kong: Institute for Monetary Research, 2011.

LEE, Keun; MALERBA, Franco. Catch-up cycles and changes in industrial leadership: windows of opportunity and responses by firms and countries in the evolution of sectoral systems. Research Policy, v. 46, n. 2, p. 338-351, mar. 2017.

LI, Lauly; TING-FANG, Cheng. Inside the US campaign to cut China out of the tech supply chain. Nikkei Asia, Tóquio, 7 out. 2020. Disponível em: <https://asia.nikkei.com/Spotlight/The-Big-Story/ Inside-the-US-campaign-to-cut-China-out-of-the-tech-supply-chain>. Acesso em: 24 out. 2020.

LIMA, Uallace Moreira. A dinâmica e o funcionamento da cadeia global de valor da indústria automobilística na economia mundial. In: OLIVEIRA, Ivan Tiago Machado; CARNEIRO, Flávio Lyrio; SILVA FILHO, Edison Benedito da (Org.). Cadeias globais de valor, políticas públicas e desenvolvimento. Brasília: Ipea, 2017a. p. 155-206.

O debate sobre o processo de desenvolvimento econômico da Coreia do Sul: uma linha alternativa de interpretação. Economia e Sociedade, v. 26, n. 3, p. 585-631, 2017b.

MEDEIROS, Carlos Aguiar de. Política Industrial e Divisão Internacional de Trabalho. Revista de Economia Política, vol. 39, nº 1 (154), pp. 71-87, janeiro-março/2019.

OECD. Interconnected economies: benefiting from global value chains. Organisation for Economic Co-operation and Development, 2013.

OECD. Investing in innovation and skills thriving in global value chains. Organisation for Economic Co-operation and Development, 2017.

OECD ILIBRARY. OECD Economic Surveys: Korea. 2020. Disponível em: <www.oecd-ilibrary.org/ economics/oecd-economic-surveys-korea_19990707>. Acesso em: 24 out. 2020.

OECD.STAT. Trade in Value Added (TiVA): principal indicators. 2020. Disponível em: <https://stats. oecd.org/Index.aspx?datasetcode=TIVA_2018_C1>. Acesso em: 24 out. 2020. 
PEREZ, Carlota; SOETE, Luc. Catching-up in technology: entry barriers and windows of opportunity. In: DOSI, Giovanni et al. (Ed.). Technical change and economic theory. Londres: Pinter Publishers, 1988. p. 458-479.

PINTO, Eduardo C.; FIANI, Ronaldo; CORRÊA, Ludmila M. Dimensões da abordagem da cadeia global de valor: upgrading, governança, políticas governamentais e propriedade intelectual. Brasília: Ipea, 2015. (Texto para Discussão n. 2.155.)

SHIGETA, Shunsuke. Abe's right-hand man wants a Japan less reliant on China. Nikkei Asia, Tóquio, 24 abr. 2020. Disponível em: <https://asia.nikkei.com/Editor-s-Picks/Interview/Abe-s-right-hand-man-wants-a-Japan-less-reliant-on-China>. Acesso em: 24 out. 2020.

SIWEI, Cheng; JIA, Denise. Chinese companies turn to Asean countries for cross-border deals. Caixin, 23 jul. 2020. Disponivel em: <www.caixinglobal.com/2020-07-23/as-europe-and-us-still-struggle-with-pandemic-focus-of-ma-activity-by-china-businesses-shifts-to-countries-and-regions-in-belt-and-road-initiative-101583350.html>. Acesso em: 24 out. 2020.

STONE, Susan; MESSENT, James; FLAIG, Dorothee. Emerging policy issues: localisation barriers to trade. OECD Trade Policy Papers, n. 180. Paris: OECD Publishing, 2015. Disponível em: <http:// dx.doi.org/10.1787/5js1m6v5qd5j-en>. Acesso em: 24 out. 2020.

STURGEON, Timothy et al. O Brasil nas cadeias globais de valor: implicações para a política industrial e de comércio. Revista Brasileira de Comércio Exterior, 2013.

THORSTENSEN, Vera; FERRAZ, Lucas; GUTIERRE, Leopoldo. O Brasil nas cadeias globais de valor. In: NEVES, Leonardo (Org.). A inserção do Brasil nas cadeias globais de valor. Cebri Dossiê, ed. esp., v. 2. Rio de Janeiro: Cebri, 2014.

TIMMER, Marcel et al. An anatomy of the global trade slowdown based on the WIOD 2016 release. University of Groningen, 2016.

TOOZE, Adam. Did Xi just save the world. Foreign Policy, Washington, D.C., 25 set. 2020. Disponível em: <https://foreignpolicy.com/2020/09/25/xi-china-climate-change-saved-the-world\%E2\%80\%A8/>. Acesso em: 24 out. 2020.

UNCTAD. World investment report 2020: international production beyond the pandemic. Genebra: United Nations Conference on Trade and Development, 2020. Disponível em: <https://unctad.org/ webflyer/world-investment-report-2020>. Acesso em: 24 out. 2020.

UNIDO. Industry 4.0: opportunities and challenges of the New Industrial Revolution for developing countries and economies in transition. United Nations Industrial Development Organization, 2016.

WADE, Robert. The role of industrial policy in developing countries. In: UNCTAD. Rethinking development strategies after the financial crisis. Genebra; Nova York: Unctad, 2015.

WHEATLEY, Alan. China circulates new strategy in economic duel with US. Asia Times Financial, Hong Kong, 5 set. 2020. Disponível em: <www.asiatimesfinancial.com/china-circulates-new-strategy-in-economic-duel-with-us>. Acesso em: 24 out. 2020.

WTO. World trade statistical review 2019. Genebra: World Trade Organization, 2019. Disponível em: <www.wto.org/english/res_e/statis_e/wts2019_e/wts19_toc_e.htm>. Acesso em: 24 out. 2020. 